\title{
WEB Device: Ready for Ruptured Aneurysms?
}

W e read with great interest the article by van Rooij et al entitled "WEB Treatment of Ruptured Intracranial Aneurysms: A Single-Center Cohort of 100 Patients." ${ }^{1}$ Following our first report on the use of Woven EndoBridge devices (WEB; Sequent Medical, Aliso Viejo, California) for ruptured aneurysms, ${ }^{2}$ this is the fourth publication to emphasize the great interest in using WEB devices to treat intracranial aneurysms in the acute phase of a subarachnoid hemorrhage. ${ }^{3,4}$ Indeed, the WEB enables fast procedures and broadens the range of aneurysms suitable for endovascular treatment without the use of material inside the parent artery: 2 points that are essential for optimal management of ruptured cases.

However, although results from these retrospective and uncontrolled cases series are promising, some points still require further investigation. Because thromboembolic complication rates appear high in ruptured WEB cases, standard procedural management of anticoagulation and aggregation should still be defined here. van Rooij et al reported a 9\% thrombotic complication rate. In a recent meta-analysis, ${ }^{5}$ thrombotic complication rates were $21 \%$ in ruptured cases versus $5 \%$ in nonruptured cases (when patients are usually premedicated with antiplatelet therapy).

In addition, the major point requiring evaluation before the expansion of this technique is the protection against bleeding offered by the device compared with standard coiling. Some cases of early rebleeding previously have been described following WEB treatment. ${ }^{6}$ We believe that rebleeding is very unlikely in cases in which WEB sizing and positioning are properly performed because intra-aneurysmal occlusion is usually very fast in ruptured cases (especially because no antiplatelet medications are used). When coils are used, a complete and compact filling of the aneurysm is required to prevent rebleeding. When one uses the WEB device, we believe that it is essential to ensure complete neck sealing to secure the aneurysm. The best way to do so is to systematically use a C-arm VasoCT (Philips Healthcare, Best, the Netherlands) ${ }^{7}$ before device detachment in ruptured cases.

To address these issues, we have initiated a prospective multicenter study that follows good clinical practice guidelines: CLinical Assessment of WEB Device in Ruptured aneurYSms. ${ }^{8}$
The primary outcome measure is the rebleed rate at 1 month. The enrollment is almost complete, and the results are expected to be available within 1 year.

\section{REFERENCES}

1. van Rooij SBT, van Rooij WJ, Peluso JP, et al. WEB treatment of ruptured intracranial aneurysms: a single-center cohort of 100 patients. AJNR Am J Neuroradiol 2017 Sep 7. [Epub ahead of print] CrossRef

2. Caroff J, Mihalea C, Dargento F, et al. Woven Endobridge (WEB) device for endovascular treatment of ruptured intracranial wideneck aneurysms: a single-center experience. Neuroradiology 2014;56: 755-61 CrossRef Medline

3. Liebig T, Kabbasch C, Strasilla C, et al. Intrasaccular flow disruption in acutely ruptured aneurysms: a multicenter retrospective review of the use of the WEB. AJNR Am J Neuroradiol 2015;36:1721-27 CrossRef Medline

4. van Rooij WJ, Peluso JP, Bechan RS, et al. WEB treatment of ruptured intracranial aneurysms. AJNR Am J Neuroradiol 2016;37:1679-83 CrossRef Medline

5. Asnafi S, Rouchaud A, Pierot L, et al. Efficacy and safety of the Woven EndoBridge (WEB) device for the treatment of intracranial aneurysms: a systematic review and meta-analysis. AJNR Am J Neuroradiol 2016;37:2287-92 CrossRef Medline

6. Caroff J, Mihalea C, Klisch J, et al. Single-layer WEBs: intrasaccular flow disrupters for aneurysm treatment-feasibility results from a European study. AJNR Am J Neuroradiol 2015;36:1942-46 CrossRef Medline

7. Caroff J, Mihalea C, Neki H, et al. Role of C-arm VasoCT in the use of endovascular WEB flow disruption in intracranial aneurysm treatment. AJNR Am J Neuroradiol 2014;35:1353-57 CrossRef Medline

8. The CLARYS trial. https://clinicaltrials.gov/ct2/show/NCT02687607. Accessed July 11, 2017

(D). Caroff

Department of Interventional Neuroradiology Bicêtre Hospital Le Kremlin-Bicêtre, France (1) J. Moret (D). Spelle Department of Interventional Neuroradiology Bicêtre Hospital Le Kremlin-Bicêtre, France Faculté de Médecine Université Paris Sud Le Kremlin-Bicêtre, France

http://dx.doi.org/10.3174/ajnr.A5367 